This item was submitted to Loughborough's Research Repository by the author.

Items in Figshare are protected by copyright, with all rights reserved, unless otherwise indicated.

\title{
Designing an occupancy flow-based controller for airport terminals
}

PLEASE CITE THE PUBLISHED VERSION

http://dx.doi.org/10.1177/0143624414540292

\section{PUBLISHER}

SAGE $\odot$ The Chartered Institution of Building Services Engineers

\section{VERSION}

AM (Accepted Manuscript)

\section{PUBLISHER STATEMENT}

This work is made available according to the conditions of the Creative Commons Attribution-NonCommercialNoDerivatives 4.0 International (CC BY-NC-ND 4.0) licence. Full details of this licence are available at: https://creativecommons.org/licenses/by-nc-nd/4.0/

\section{LICENCE}

CC BY-NC-ND 4.0

\section{REPOSITORY RECORD}

Mambo, Abdulhameed D., Mahroo Eftekhari, Thomas Steffen, and M.W. Ahmad. 2015. "Designing an Occupancy Flow-based Controller for Airport Terminals". figshare. https://hdl.handle.net/2134/17429. 


\title{
DESIGNING AN OCCUPANCY FLOW-BASED CONTROLLER FOR AIRPORT TERMINALS
}

\author{
${ }^{1}$ Mambo D. A. (PhD), ${ }^{2}$ Eftekhari M.M (PhD), ${ }^{3}$ Steffen T (PhD) \& ${ }^{4}$ Ahmad, M.W(PhD).
}

\author{
1Department of Building, Federal University of Technology, PMB 65 Minna, Nigeria, \\ ${ }^{2}$ School of Civil Engineering, Loughborough University, LE11 3TU, UK \\ ${ }^{3}$ School of Aeronautical, Automotive, Chemical and Materials Engineering, \\ Loughborough University, LE11 3TU, UK \\ ${ }^{4}$ School of Engineering, BRE Centre for Sustainable Construction, Cardiff University, Cardiff \\ CF24 3AA, UK
}

Corresponding email address: A.D.Mambo@lboro.ac.uk

\begin{abstract}
One of the most cost effective ways to save energy in commercial buildings is through designing a dedicated controller for adjusting environmental set-points according occupancy flow. This paper presents the design of a fuzzy rule-based supervisory controller for reducing energy consumptions while simultaneously providing comfort for passengers in a large airport terminal building. The inputs to the controller are the time schedule of the arrival and departure of passenger planes as well as the expected number of passengers, zone global illuminance (daylight) and external temperature. The outputs from the controller are optimised temperature, airflow and lighting set-point profiles for the building. The supervisory controller was designed based on expert knowledge in MATLAB/Simulink, and then validated using simulation studies. The simulation results demonstrate significant potential for energy savings in the controller's ability to maintain comfort by adjusting setpoints according to the flow of passengers.
\end{abstract}

\section{PRACTICAL APPLICATION}

The systematic approach adopted here, including the use of artificial intelligence to design supervisory controllers, can be extended to other large buildings which have variable but predictable occupancy patterns like the restricted area of the airport terminal building.

\section{KEYWORDS}

Building Control, Indoor Comfort, Airport Terminal's $\mathrm{CO}_{2}$ Emission Savings, Fuzzy Rule-Based Supervisory Controller

\section{INTRODUCTION}


UK sets an ambitious target for overall CO2 reductions of $80 \%$ by 2050 relative to 1990 level (1) as her contribution in the global effort at combating global warming and climate change. Aviation contributes only about $6.3 \%$ of UK's carbon emission (2). It may be argued that this impact is low but the projected growth in aviation is of growing concern; UK's aviation is growing at approximately $8 \%$ per annum and as highlighted by the Tyndall integrated scenarios project, under some growth projections, the lion's share of the UK's allowable CO2 emissions will be derived from aviation by 2050(3). This suggests that aviation will remain in the political spotlight for the foreseeable future and against this background, every sector of the industry will have to demonstrate action to minimise $\mathrm{CO} 2$ emissions. At the same time, emissions taxes, airline and airport $\mathrm{CO}_{2}$ limits, and emissions trading schemes will increase operating costs creating financial pressures for carbon reduction(4). As such energy managers at various airports across UK are continuing to demonstrate their commitment to climate change by carrying out energy efficient measures. Edinburgh Airport has taken effort to lighten its electricity and gas consumption(5) while Manchester have set target to achieve carbon neutrality in her energy and vehicle use(6).

In addition, building energy consumption has already reached over $40 \%$ of the total global energy consumption and has since surpassed other economic sectors (7). So, while building engineers may not influence fuel or engine technology in airports, they can help to significantly reduce or eliminate carbon emissions associated with designing and adapting airport infrastructure. Therefore, to achieve any meaningful emission savings in UK airports, terminal buildings' energy use must be given adequate attention.

HVAC and lighting systems in commercial buildings need to be carefully controlled to provide comfort under a range of changing load conditions. This is a difficult task, and therefore efficient and effective control is often the most cost-effective way to improve the energy efficiency of a building. Airport buildings are operated round-the-clock and contain many spaces that are different in function and structure; these leads to complicated building systems including heating, ventilation, air-conditioning, electric lighting and hot water systems that can be difficult to control. This complexity is enhanced by non-linear effects, time-varying and uncertain nature of the variables inside and outside of the building affecting these systems requiring frequent adjustment of comfort set-point. PID controllers currently deployed in managing such buildings are only able to deal with non-linearity within small range of building operating conditions and generally, occupancy based control strategies are not achieved through the use of conventional controllers alone. Consequently, typical HVAC and Lighting systems are run continuously on conservative settings chosen for maximum comfort and maximum ventilation power. This leads to a high energy consumption, a good part of which is wasted during periods of low occupancy (8) or in the thesis at Loughborough University (9). 
The advantage Fuzzy logic control offers to building energy management is that it does not require information about plant dynamics and is capable of approximating any real function on a compact fuzzy set(10) and because human sensation of comfort is not crispy but fuzzy and subjective, classical adaptive controllers requiring crisp comfort inputs compared poorly to fuzzy logic controllers which are robust as well and are well adapted to regulate fuzzy items in buildings $(11,12)$.

Table 1 summarises the strength and weaknesses of the various control types implemented in buildings and similar summary with different objective can be found in a review paper (13). The summary showed that fuzzy supervisory controllers are capable of extending the capacity of the conventional PID control paradigm to coupe with challenging applications.

TABLE 1: SUMMARY OF EXISTING WORKS

\begin{tabular}{|c|c|c|c|c|c|c|c|c|c|}
\hline $\begin{array}{l}\text { Control } \\
\text { Systems }\end{array}$ & $\begin{array}{l}\text { Thermal } \\
\text { Control }\end{array}$ & $\begin{array}{c}\text { Ventilation } \\
\text { Control }\end{array}$ & $\begin{array}{l}\text { Lighting } \\
\text { Control }\end{array}$ & $\begin{array}{c}\text { Energy } \\
\text { Reduction }\end{array}$ & $\begin{array}{c}\text { Learning/ } \\
\text { Adaptation }\end{array}$ & $\begin{array}{c}\text { Tuning } \\
\text { Local } \\
\text { Controllers }\end{array}$ & $\begin{array}{c}\text { Setpoint } \\
\text { Pre- } \\
\text { Processing }\end{array}$ & $\begin{array}{c}\text { Occupancy } \\
\text { Control }\end{array}$ & References \\
\hline ON/OFF & $\checkmark$ & - & - & - & - & - & - & - & (14) \\
\hline PID & $\checkmark$ & & & - & - & - & - & - & $(13-19)$ \\
\hline $\begin{array}{l}\text { Optimal } \\
\text { Control }\end{array}$ & & $\checkmark$ & - & $\checkmark$ & $\checkmark$ & - & - & - & $\begin{array}{l}(15,20,21,21,22,22- \\
25)\end{array}$ \\
\hline $\begin{array}{l}\text { Predictive } \\
\text { Control }\end{array}$ & $\checkmark$ & $\checkmark$ & - & $\checkmark$ & $\checkmark$ & - & - & $\checkmark$ & $(23,23,26-31)$ \\
\hline $\begin{array}{l}\text { Genetic } \\
\text { Algorithm }\end{array}$ & $\checkmark$ & - & - & $\checkmark$ & $\checkmark$ & & - & - & $(22,32-41)$ \\
\hline $\begin{array}{l}\text { Neural } \\
\text { Network } \\
\text { Control }\end{array}$ & $\checkmark$ & - & - & $\checkmark$ & $\checkmark$ & - & - & $\checkmark$ & $(31,37,42-49)$ \\
\hline $\begin{array}{l}\text { Fuzzy Local } \\
\text { control }\end{array}$ & $\checkmark$ & $\checkmark$ & $\checkmark$ & - & & - & - & - & $\begin{array}{l}(12,25,25,38,50- \\
54)\end{array}$ \\
\hline $\begin{array}{l}\text { Fuzzy } \\
\text { Supervisory } \\
\text { Control }\end{array}$ & $\checkmark$ & $\checkmark$ & $\checkmark$ & $\checkmark$ & $\checkmark$ & $\checkmark$ & - & - & $(28,52,53,55-65)$ \\
\hline
\end{tabular}

This paper presents the design of a fuzzy supervisory controller for managing the indoor comfort of an airport terminal and examines its benefits. A detailed simulation model is used to determine the effects in terms of energy and carbon emission reduction as well as passenger comfort in a UK airport terminal.

\section{AREA OF FocUS FOR THE Airport CONTROL STRATEGy}

This supervisory control strategy was developed for the zones that are used mainly by the passengers and staff of the airport; such that the occupancy flow pattern is directly related to flight schedules. Airport buildings are often zoned such that the landside areas accessible to the general public are separated from the airside areas that are only restricted to the passengers and staff with relevant documents. This study will focus on the departure/arrival 
gates only, because they typically have well understood occupancy patterns. Other zones such as shops and leisure areas have more complex occupancy patterns that are beyond the scope of this paper. This differentiation is necessary in order to capture areas within the terminal where occupancy can be predicted using available information on arriving and departing passenger planes.

In general, terminal arrival process is less complicated than departure, since arriving passengers are mostly interested in picking their baggage and checking-out quickly. This process is usually short and largely predictable. The departure process takes a much longer time, partially because of airline procedures, and partially because passengers will arrive early to allow for possible delays in transportation to the airport. The International Civil Aviation Organisation (ICAO) recommends forty-five minutes as the maximum duration for international arrival passenger processing from disembarkation to completion of the last clearance process, and one hour for the departing passenger from clearance to embarkation (66). In a survey (67) conducted in seven UK airports by Civil Aviation Authority [CAA] in 2009 shows that the typical processing time for most passengers in these airports was even shorter than the provisions in the standard.

\section{FUZZY SUPERVISORY CONTROLLER}

The main goal of supervisory control is to increase the operating availability of set-points for the process under control based on the function of the control space (figure 1). To achieve this, the controller supplies set-points to coordinates the actions of the distributed controllers according to the evolution of the passenger flows and external conditions.

A fuzzy supervisory controller was chosen because it provides a direct way to translate observations of the arrival and departure process into control actions. The heuristic elements in the control strategy are based on operator knowledge obtained from building operation and in-situ measurements of control variable carried in the building.

This structure of the supervisory controller follows the framework of Yokogawa electric's temperature controller (68). In this design, the fuzzy supervisory module leads the PID controller along a temperature trajectory that can quickly reach the actual set-points without overshoot. A key difference is that Yokogawa controller is a close-loop supervisory control system and involves only temperature, while the one described here is an open-loop (feedforward) system. This change simplifies the design of the supervisory controller, and it avoids potential stability issues caused by the interference of two feedback loops. Vogrin and Halang demonstrated the use of a set-point pre-processor with a similar architecture to control robot arm. This experiment found that the controller response speed is very high, and it maintains good closed loop stability (69). The major limitation of a static controller such as this one is that it does not take the dynamics of the system into account but dynamic control is of course applied on the lower level, so that the system will respond 
perfectly to changing operating conditions. So compared to the high level control goals set for this paper, this is still a good approach.

The structure is shown in Figure 1, and the used variables are explained in Table 2.

One of the advantages of this scheme is that the fuzzy supervisory controller can compensate for an expected error $E(t)$ in the PID control loop by moving the set-point $Y_{B}(t)$ beyond the value that is actually desired. This means that the controller error $E(t)$, the difference between the set-point schedule and the actual value $Y_{B}(t)-Y(t)$ is less than the controlled error $Y_{A}(t)-Y(t)$ obtained by using conventional controller alone.

The supervisory controller receives data on when a plane is to land or to take-off, and the number of passengers estimated from the size of the anticipated aircraft type. This kind of data is available from the passengers' information desk long before the actual flight. Further inputs are real-time hourly measurements of external temperature and sub-hourly measurements of zone horizontal illuminance from daylight sensors.

The supervisory fuzzy controller provides the required thermal, lighting and indoor airquality comfort set-points to the identified zones in the terminal where the passengers will be transiting. These set-points are available in advance to the passengers arriving, allowing the systems to raise or lower the indoor conditions despite the time delay inherent in the heating system. For an arriving aircraft, the set-points are set when an aircraft touches down, which is typically 15 minutes before the passengers disembark into the building. This duration was confirmed in simulation to be sufficient for the HVAC system to provide a good thermal comfort environment. They are set to elapse about an hour after arrival, at which time the passengers should have cleared the zone. For departing passengers, the opposite sequence was used: set-points are chosen for the gate zone an hour before the scheduled departure, and they are reset once boarding is completed.

\section{STRUCTURE OF FuZZY CONTROLLER}

The fuzzy controller was developed using the Fuzzy Logic Tool Box(70) in MATLAB. It comprises the fuzzifier which determines the membership degrees of the controller crisps input values in the antecedent fuzzy sets. The inference mechanism combines this information with the knowledge stored in the rules to determine what the output of the rule-based system should be. The output is a fuzzy set but for control purposes, a crisp control signal is required. The defuzzifier calculates the value of this crisp signal from the fuzzy controller outputs (71).

This controller (Figure 2) takes Outdoor Temperature (OT), Zone Illuminance (ZI), Passenger Numbers (PN) at a given flight time as inputs and outputs indoor Lighting Setpoints (LS), Temperature Set-point (TS) and Airflow Rates (AR) for the zones. The varying range of OT, ZI, $P N, L S, T S$ and AR are described using linguistic terms. The discourse domains in the fuzzy set are between -10 to 35 degree Celsius for OT, 0 to 500 for PN, 0 to 30 degree Celsius for 
TS, 0 to 400 lux for ZI, 0 to 250 lux for LS and 0 to 50000 litres per seconds for AR. Fuzzification was effected using the triangular membership function. Defuzzification was achieved using the centroid of area (averaging) method, because this supervisory controller does not have to resolve conflicting resolution strategies

\section{CONSTRUCTION OF FUZZY RULES}

The heuristic rules mapping inputs to outputs was defined using linguistic terms (Table 2) such as if Outside Temperature is Cold, Zone Illuminance is Dark and the Passenger Number is Many then provide Winter temperature set-points, lighting is Bright and Airflow Rates is Many. An unoccupancy scenario might read if Outside Temperature is Cold, Passenger Number is None and Zone Illuminance is Dark then provide Winter-un-occupied temperature set-point, Light Levels is Off and Airflow Rate is Un-occupied.

The thirty-six fuzzy rules for this controller were defined using Mamdani Fuzzy Modelling (72). In this approach, the antecedent and the consequent proposition are expressed linguistically. The connectives between the inputs and the outputs rules is the logical 'and' operand. The linguistic terms are summarised in Table 3. The detailed control signal takes too much space to present here, but it can be found in (8) or in the thesis at Loughborough University .

\section{CASE Study OF Airport BuILDing}

The case study is a UK airport terminal. This terminal was constructed in 1992 on the NorthWest part of the airport site. The terminal is made up of five-floor central building covering a gross floor area of about $18,000 \mathrm{~m}^{2}$ and has two piers of four floor levels measuring about $5,400 \mathrm{~m}^{2}$ spanning to the left and right direction of the central building. The ground and the first floor contain the arrival halls, the third floor, the departure halls, and the fourth floor is made up of lounges, offices and the control room on the central building it mainly housed the plant rooms on the piers. The fifth floor is mainly plant rooms. So the building is already separated based on the airport function.

The building's hot water is provided by gas boilers located in the central and eastside of the terminal. For cooling, there are air-cooled chillers externally located on steelwork frames in the main plant rooms. The air handling units comprises of Inlet damper, mixing box, HPHW Frost Coil, Panel Filter, Bag Filter, Carbon Filter, Cooling Coil, HPHW Re-heat Coil, Supply Fan, Extract Fan. The building has no lighting and Dayligthing control but the luminaries are currently being upgraded and the installation of lighting control is being considered. For the purpose of this study, lighting control is included as part of the energy use model.

This terminal is a jet only terminal with low cost, charter and long haul carriers. The smallest regular aircraft type is the B737-300 with 148 seats, and the largest is Virgin's B747-400 with 456 seats. This information was used to estimates the passenger number per giving flight time. The flight arrival and departure data was collected from the Airport Information Desk, 
a central database containing the flight information. The external temperature data for the simulation was retrieved from the British Atmospheric Data Centre (BADC). The airport building has large glass window areas which is suitable for daylight control. Available illuminance for the period of October 26th to November $2^{\text {nd }}$ was estimated from global and diffuse horizontal illuminance variation based on ten years of measurements by the Building Research Establishment (BRE) (73). The weather data used in this model was the hourly ASHRAE International Weather for Energy Calculation (IWEC) GBR Manchester Ringway MN6 data.

\section{Modelling of BuILDING GEOMETRY AND HVAC SYSTEMS}

The building geometry was modelled in DesignBuilder by importing the 2D AutoCAD drawings of the building. The external walls were traced, and the building zones defined based on occupancy type and according to the segmentation of the HVAC system in the indoor space for each of the floors. The thermal zone calculation method in DesignBuilder is a heat balance model. The basic assumption of heat balance models is that air in each thermal zone can be modelled as well stirred with uniform temperature throughout. This is a little different from reality but computationally cost-effective compare to detailed CFD modelling. In reality, most zones in airports are open to surrounding areas, making independent control of a zone difficult. Still, heat transfer between zones is typically small, because the predominant air flow is vertical and not horizontal. Figure 3 shows the resulting $3 \mathrm{D}$ geometry of the building.

For this case study, there were twenty-two thermal zones in the building. However, these zones were further sub-grouped into six zone groups according to the HVAC system type. The building model was zoned according to passenger flow such that the areas accessible to the public were separated from the areas that were restricted to only passengers and staff. Occupancy in the restricted areas such as the check-in, customs, security, passport control and baggage reclaim areas can easily be linked to arriving/departing passenger planes. However, in the public spaces such as the booking hall, some retail areas and some offices, the flow of people depends on many factors that are difficult to estimate, making them more complicated to control. The model was checked by ensuring that occupancy data was inherited correctly so that changes at block and building level produce the needed effect.

\section{FUZZY CONTROLLER SIMULATION AND DISCUSSION}

The controller supplied comfort set-point for 45 minutes, 1 hour and 2 hours before the next departure time and then relapses to the setback mode until 45 minutes, 1 hour and 2 hours before next departure. For arrival, comfort setpoints is relapsed to setback mode 45 minutes, 1 hour and 2 hours after arrival as shown in Figure 4.

These times were chosen to gauge the benefit in terms of energy use and comfort when comfort set-points from the controller are ran for: 
a period less than standard processing times ( 45 minutes) to simulate the maximum passenger processing times recorded in CAA survey (67)

a standard processing time (1 hour) as recommended by ICAO (66)

a rare extended processing time ( 2 hour) to accommodate delays in passenger processing.

Figure 5, 6 and 7, shows how the controller rules connect input variables to output variables.

Figure 5 shows how temperature set-points (TS) change in relation to passenger numbers (NP) and external temperature (OT). For example; when the zone is un-occupied (passenger number is zero) and external temperature is less $10^{\circ} \mathrm{C}$ (during winter) or over $20{ }^{\circ} \mathrm{C}$ (summer); the controller relapses the set-point to its setback temperature of about $12{ }^{\circ} \mathrm{C}$ (winter) or $23^{\circ} \mathrm{C}$ (summer) to conserve energy. However, when the place becomes occupied, the controller provides comfort set-points commensurate with the comfort requirement for that zone based on whether outside condition is winter, midseason or summer. There is still a variation in set-point to accommodate for different temperature perception depending on the season, but the changes are much smaller relative to standard room temperature of $20{ }^{\circ} \mathrm{C}$. Therefore, temperature set-points depend both on occupancy and changes in external conditions.

Air Flow rates $(A R)$ as in figure 6 on the other hand varies directly with the estimated arriving or departing passengers at a giving time. This explained the rise in airflow rates (AR) as the passenger numbers (NP) increases. Ten litres per second per person was provided for each passenger being the minimum fresh air requirement recommended by CIBSE (74) for such place.

During period of unoccupancy, up to 1000 litres per second is still provided to support nonpassenger activities.

Lighting set-points (LS) of 200 lux was provided when occupancy was predicted to occur and it is off when the zone was unoccupied as shown in figure 7. This was because according to CIBSE Guide A (74) 200 lux is recommended as minimum for most indoor spaces within the terminal except offices and shop areas. Dayligthing control was also included as the lights are dimed or switched-off depending on the adequacy of the daylight illuminance within the zone. This lighting control does not include security and a task light that may be used by the staff if higher illuminance values are required the desk for passenger processing.

The set-points for heating, airflow rate and lighting supplied by the supervisory controller in SIMULINK were converted EnergyPlus compact schedules and then applied to the building model in DesignBuilder. This simple implementation is possible because the supervisory controller uses no feedback, so it does not depend on measurements from within the building. 


\section{Simulations in DesignBUiLDER}

In the baseline scenario, HVAC and lighting systems were scheduled to run for 24 hours and a temperature set-point of between $21^{\circ} \mathrm{C}$ and $23^{\circ} \mathrm{C}$ was applied to all the indoor spaces of the terminal building to simulate the average condition of what was observed from the indoor monitoring results carried out in the airport as reported in(8). For the energy saving scenario, compact schedules generated from the fuzzy controller outputs for temperature set-point, lighting set-point and airflow rates schedules were incrementally applied to the selected indoor spaces (check-in, customs area, gates etc.) while other indoor spaces (offices, shops etc.) were run on full schedules.

\section{RESULTS}

The simulation results are shown in Figure 8. In the legend, the abbreviations shown in Table 3 are used for Figure 8, 9, and 10.

From Figure 8 , it can be seen that due temperature setback during un-occupy period, comfort during occupancy increased from slightly warm to almost neutral, airflow rates setback on the other hand caused an increase in discomfort which was restored by the fall in lighting gains due to lighting control. Comfort level also increase from a PMV value of between 1.1 and 0.9 to between 0.2 and 0.4 for the winter week considered. An indoor thermal environment that has a PPD of less than $10 \%$ corresponding to a PMV of about \pm 0.50 is considered acceptable (75). For transitional spaces like the airport a PMV of \pm 1 is still acceptable $(76,77)$. Energy and $\mathrm{CO}_{2}$ savings of between $45 \%$ to $48 \%$ and $42 \%$ to $45 \%$ respectively can be observed for this scenario.

From Figure 9 and was the case with the previous scenario in Figure 8, temperature setback, improves comfort rating, scheduled airflow rates degrade comfort but lighting schedules improve comfort the most. The comfort level also increased from a PMV value of between 1.1 and 0.9 to between 0.8 and 1 for the winter week considered. Also energy and $\mathrm{CO}_{2}$ savings of between $42 \%$ to $50 \%$ and $33 \%$ to $37 \%$ respectively can be observed for this scenario. These results shows a reduction in savings and degradation in comfort level compare to the 45 minutes elapse time.

Similarly, from figure 10, because of the longer set-point elapse time, energy and $\mathrm{CO}_{2}$ savings of between $41 \%$ to $48 \%$ and $30 \%$ to $34 \%$ respectively can be observed for this scenario. The comfort level also increased from a PMV value of between 1.1 and 0.9 to between 0.5 and 0.7 for the winter week considered. Although the savings in energy and carbon emission is less compare to the previous scenarios, comfort is better compare to the 1 hour elapse time.

Similar results was obtained for summer scenario where an energy savings of $21 \%$ to $27 \%$ achieved was less than the $40 \%$ to $50 \%$ recorded for the winter time. This was because summer times are busier for the airports as such there are less time available to implement 
energy conservation measure other than just applying the right comfort setpoints. Also, the need for active cooling or heating is generally less considering the prevailing external weather data. The result for energy savings seems to suggest that the 1 hour setpoints elapse time provided the greatest savings compare to 45 minutes and 2 hours while expectedly, the 2 hours elapse time provided the fewest savings.

\section{LIMITATIONS OF THIS STUDY}

Due to the frame of the project, it was possible to take real measurements at the airport building, but the controller could not be tested there. Therefore, the results are based on simulation models, which while accurate and verified, may deviate slightly from real life performance. This applies both to the details of the building physics such as lateral heat transfer between zones, and to the random nature of occupant behaviour. Some of the dynamic aspects of the HVAC system have also been neglected in the model. More details on the modelling can be found in (8).

Because of these differences, applying the controller presented here will not result in the best possible result, and it may not provide savings of the predicted size. However, after proper re-tuning of the controller, similar savings should be achievable.

\section{CONCLUSIONS}

This paper presents the design of a fuzzy supervisory controller in MATLAB/SIMULINK. Its performance was analysed using the thermal model of an existing airport terminal building as a case study. With professional building software, various set-point elapse time and setback operations were investigated. Specifically, the setback operation based on the real time flight schedule, and comfort set-points were applied for both HVAC and lighting in airport terminal building during expected occupancy periods. Simulation results in MATLAB investigating these variable set-points elapse/setback time, passenger numbers and external conditions produces optimised set-points for lighting, heating and airflow rates. Through integrated dynamic simulation in DesignBuilder, these optimised building HVAC and lighting control systems set-points were rated in terms of energy and $\mathrm{CO}_{2}$ emission savings and comfort vote. The result shows that setback operations based on passengers' occupancy profile could save up to $48 \%$ of energy and $45 \%$ of carbon emission in winter and $21 \%-27 \%$ for both energy and carbon emission in summer while still maintaining comfort compare to the baseline scenario. Further improvements of this approach are possible. The current controller is essentially static with pre-defined fixed time scales. Accounting for the dynamics of the HVAC system and considering differences in passenger behaviour could lead to further improvements.

\section{ACKNOWLEDGEMENT}

The authors gratefully acknowledge the support of Manchester Airport Group for facilitating the effort on data collection. We also acknowledge the financial support provided by the 
Engineering and Physical Sciences Research Council, UK in its Airport Sandpits Programme and Petroleum Technology Development fund (PTDF) Nigeria.

\section{REFERENCES}

(1) Climate Change Act 2008. Available at: http://www.legislation.gov.uk/ukpga/2008/27/contents. Accessed 9/11/2013, 2013.

(2) Pejovic T, Noland RB, Williams V, Toumi R. Estimates of UK CO 2 emissions from aviation using air traffic data. Clim Change 2008;88(3):367-384.

(3) Anderson K. Decarbonising the UK: Energy for a climate conscious future. : Tyndall Centre for Climate Change Research; 2005.

(4) Centre for Air Transport and the Environment - Carbon management. Available at: http://www.cate.mmu.ac.uk/research-themes/environmental-capacity-at-airports/carbon-management/. Accessed 9/11/2013, 2013.

(5) Edinburgh Airport tops UK Carbon League Table. Available at: http://www.edinburghairport.com/aboutus/media-centre/press-releases/2013/03/27/edinburgh-airport-tops-uk-carbon-league-table. Accessed 9/11/2013, 2013.

(6) Sustainable Aviation - Manchester Airport's Environmental Commitment. Available at: http://www.sustainableaviation.co.uk/pages/news/manchester-airports-environmental-commitment.html.

Accessed 9/11/2013, 2013

(7) Perez-Lombard L, Ortiz J, Pout C. A review on buildings energy consumption information. Energy Build 2008;40(3):394-398.

(8) Mambo DA, Efthekhari M, Steffen T. Occupancy-driven supervisory control strategies to minimise energy consumption of airport terminal building. Sustainability in Energy and Buildings: Springer; 2013. p. 479-489.

(9) Abdulhameed D. Mambo. Occupancy Driven Supervisory Control of Indoor Environment Systems to Minimise Energy Consumption of Airport Terminal Building. United Kingdom: Loughborough University; 2013.

(10) Singh J. Review: Health, Comfort and Productivity in the Indoor Environment. Indoor and Built Environment 1996;5(1):22-33.

(11) Dounis A, Santamouris M, Lefas C, Argiriou A. Design of a fuzzy set environment comfort system. Energy Build 1995;22(1):81-87.

(12) A fuzzy control system based on the human sensation of thermal comfort. Fuzzy Systems Proceedings, 1998. IEEE World Congress on Computational Intelligence., The 1998 IEEE International Conference on: IEEE; 1998.

(13) Dounis AI, Caraiscos C. Advanced control systems engineering for energy and comfort management in a building environment—A review. Renewable and Sustainable Energy Reviews 2009;13(6):1246-1261.

(14) Levermore G. Building control systems-CIBSE guide H. 2000. 
(15) A survey of control technologies in the building automation industry. 16th IFAC World Congress; 2005.

(16) Bhatia A. Fudermental of HVAC Controls. 2012; Available at: http://www.cs.berkeley.edu/ culler/cs294f09/m197content.pdf. Accessed 01/26, 2013.

(17) Skogestad S. Simple analytic rules for model reduction and PID controller tuning. J Process Control 2003;13(4):291-309.

(18) Visioli A. Practical PID Control. : Springer; 2006.

(19) PID controllers: recent tuning methods and design to specification. Control Theory and Applications, IEE Proceedings-: IET; 2002.

(20) Optimal tuning of PID controllers for first order plus time delay models using dimensional analysis. Control and Automation, 2003. ICCA'03. Proceedings. 4th International Conference on: IEEE; 2003.

(21) Todorov E. Optimal control theory. Bayesian brain: probabilistic approaches to neural coding 2006:269298.

(22) Wang S, Jin X. Model-based optimal control of VAV air-conditioning system using genetic algorithm. Build Environ 2000;35(6):471-487.

(23) Henze GP, Dodier RH, Krarti M. Development of a predictive optimal controller for thermal energy storage systems. HVAC\&R Research 1997;3(3):233-264.

(24) Xu X, Wang S, Sun Z, Xiao F. A model-based optimal ventilation control strategy of multi-zone VAV airconditioning systems. Appl Therm Eng 2009;29(1):91-104.

(25) Li H, Zhang L, Cai K, Chen G. An improved robust fuzzy-PID controller with optimal fuzzy reasoning. Systems, Man, and Cybernetics, Part B: Cybernetics, IEEE Transactions on 2005;35(6):1283-1294.

(26) Energy efficient building climate control using stochastic model predictive control and weather predictions. American Control Conference (ACC), 2010: IEEE; 2010.

(27) Xu M, Li S. Practical generalized predictive control with decentralized identification approach to HVAC systems. Energy conversion and management 2007;48(1):292-299.

(28) He M, Cai WJ, Li SY. Multiple fuzzy model-based temperature predictive control for HVAC systems. Inf Sci 2005;169(1):155-174.

(29) Henze GP, Kalz DE, Liu S, Felsmann C. Experimental analysis of model-based predictive optimal control for active and passive building thermal storage inventory. HVAC\&R Research 2005;11(2):189-213.

(30) Maciejowski JM. Predictive control: with constraints. : Pearson education; 2002.

(31) Curtiss PS, Kreider JF, Brandemuehl J, American Society of Heating R, Air-Conditioning Engineers. Adaptive Control of HVAC Processes Using Predictive Neural Networks. : American Society of Heating, Refrigerating and Air-Conditioning Engineers; 1993.

(32) Ooka R, Komamura K. Optimal design method for building energy systems using genetic algorithms. Build Environ 2009;44(7):1538-1544. 
(33) Nassif N, Kajl S, Sabourin R. Optimization of HVAC control system strategy using two-objective genetic algorithm. HVAC\&R Research 2005;11(3):459-486.

(34) Nassif N, Kajl S, Sabourin R. Optimization of HVAC control system strategy using two-objective genetic algorithm. HVAC\&R Research 2005;11(3):459-486.

(35) Wang W, Zmeureanu R, Rivard H. Applying multi-objective genetic algorithms in green building design optimization. Build Environ 2005;40(11):1512-1525.

(36) Alcalá R, Benítez JM, Casillas J, Cordón O, Pérez R. Fuzzy control of HVAC systems optimized by genetic algorithms. Appl Intell 2003;18(2):155-177.

(37) Chow T, Zhang G, Lin Z, Song C. Global optimization of absorption chiller system by genetic algorithm and neural network. Energy Build 2002;34(1):103-109.

(38) Kolokotsa D, Stavrakakis GS, Kalaitzakis K, Agoris D. Genetic algorithms optimized fuzzy controller for the indoor environmental management in buildings implemented using PLC and local operating networks. Eng Appl Artif Intell 2002 9;15(5):417-428.

(39) Wright JA, Loosemore HA, Farmani R. Optimization of building thermal design and control by multicriterion genetic algorithm. Energy Build 2002;34(9):959-972.

(40) Wang S, Jin X. Model-based optimal control of VAV air-conditioning system using genetic algorithm. Build Environ 2000;35(6):471-487.

(41) Online genetic algorithm tuning of a PI controller for a heating system. Genetic Algorithms In Engineering Systems: Innovations And Applications, 1997. GALESIA 97. Second International Conference On (Conf. Publ. No. 446): IET; 1997.

(42) Wong S, Wan KK, Lam TN. Artificial neural networks for energy analysis of office buildings with daylighting. Appl Energy 2010;87(2):551-557.

(43) Yokoyama R, Wakui T, Satake R. Prediction of energy demands using neural network with model identification by global optimization. Energy Conversion and Management 2009;50(2):319-327.

(44) Yang J, Rivard H, Zmeureanu R. On-line building energy prediction using adaptive artificial neural networks. Energy Build 2005;37(12):1250-1259.

(45) Dodier RH, Henze GP. Statistical analysis of neural networks as applied to building energy prediction. Journal of solar energy engineering 2004;126(1):592-600.

(46) Ben-Nakhi AE, Mahmoud MA. Energy conservation in buildings through efficient A/C control using neural networks. Appl Energy 2002;73(1):5-23.

(47) Kalogirou SA, Bojic M. Artificial neural networks for the prediction of the energy consumption of a passive solar building. Energy 2000 5;25(5):479-491.

(48) Han Y, Xiu L, Wang Z, Chen Q, Tan S. Artificial neural networks controlled fast valving in a power generation plant. Neural Networks, IEEE Transactions on 1997;8(2):373-389. 
(49) Hepworth S, Dexter A, Willis S. Neural network control of a non-linear heater battery. Building Services Engineering Research and Technology 1994;15(3):119-129.

(50) Alcalá R, Alcalá-Fdez J, Gacto MJ, Herrera F. Improving fuzzy logic controllers obtained by experts: a case study in HVAC systems. Appl Intell 2009;31(1):15-30.

(51) Soyguder S, Alli H. Predicting of fan speed for energy saving in HVAC system based on adaptive network based fuzzy inference system. Expert Syst Appl 2009;36(4):8631-8638.

(52) Soyguder S, Karakose M, Alli H. Design and simulation of self-tuning PID-type fuzzy adaptive control for an expert HVAC system. Expert Syst Appl 2009;36(3):4566-4573.

(53) Gouda M, Danaher S, Underwood C. Thermal comfort based fuzzy logic controller. Building services engineering research and technology 2001;22(4):237-253.

(54) Shahnawaz Ahmed S, Shah Majid M, Novia H, Abd Rahman H. Fuzzy logic based energy saving technique for a central air conditioning system. Energy 2007;32(7):1222-1234.

(55) Tuning of PID controllers with fuzzy logic. Control Theory and Applications, IEE Proceedings-: IET; 2001.

(56) Bruant M, Guarracino G, Michel P. Design and tuning of a fuzzy controller for indoor air quality and thermal comfort management. Int J Sol Energy 2001;21(2-3):81-109.

(57) Calvino F, La Gennusa M, Rizzo G, Scaccianoce G. The control of indoor thermal comfort conditions: introducing a fuzzy adaptive controller. Energy Build 2004;36(2):97-102.

(58) Kolokotsa D, Niachou K, Geros V, Kalaitzakis K, Stavrakakis G, Santamouris M. Implementation of an integrated indoor environment and energy management system. Energy Build 2005;37(1):93-99.

(59) Soyguder S, Alli H. An expert system for the humidity and temperature control in HVAC systems using ANFIS and optimization with Fuzzy Modeling Approach. Energy Build 2009;41(8):814-822.

(60) An integrated control system for optimizing the energy consumption and user comfort in buildings. Computer Aided Control System Design, 2002. Proceedings. 2002 IEEE International Symposium on: IEEE; 2002.

(61) Doukas H, Patlitzianas KD, Iatropoulos K, Psarras J. Intelligent building energy management system using rule sets. Build Environ 2007;42(10):3562-3569.

(62) Kristl Ž, Košir M, Trobec Lah M, Krainer A. Fuzzy control system for thermal and visual comfort in building. Renewable Energy 2008;33(4):694-702.

(63) Guillaume S, Charnomordic B. Fuzzy inference systems: An integrated modeling environment for collaboration between expert knowledge and data using FisPro. Expert Syst Appl 2012 8;39(10):8744-8755.

(64) Guillemin A, Morel N. An innovative lighting controller integrated in a self-adaptive building control system. Energy Build 2001;33(5):477-487.

(65) Eftekhari M, Marjanovic L. Application of fuzzy control in naturally ventilated buildings for summer conditions. Energy Build 2003;35(7):645-655. 
(66) ICAO. International Standards and Recommended Practice, Annex 9 to the convention of International Civil Aviation Organisation -Facilitation. 2005; Available at: http://dcaa.trafikstyrelsen.dk:8000/icaodocs/Annex\%209\%20-\%20Facilitation/Facilition.pdf. Accessed 11/2012, 2012.

(67) DfT. Air passenger experience: Results from CAA survey module (2009). 2010; Available at: https://www.gov.uk/government/publications/air-passenger-experience-results-from-caa-survey-module-2009.

(68) Chiu S. Using fuzzy logic in control applications: beyond fuzzy PID control. Control Systems, IEEE 1998;18(5):100-104.

(69) Vogrin P, Halang WA. A programmable inference controller meeting highest safety requirements. Journal of Automation Mobile Robotics and Intelligent Systems 2010;4(1):8-19.

(70) Mathworks I. Fuzzy Logic Toolbox: User's Guide, 2007.

(71) Passino KM, Yurkovich S. Fuzzy control. : Citeseer; 1998.

(72) Mamdani EH. Application of fuzzy logic algorithm for control of simple dynamic plant. Proceeding of Institute of Electrical Engineering 1974;121(12):1585-1588.

(73) Hunt D. Availability of Daylight. Garston: BREPress; 1979.

(74) CIBSE. Guide A: Environmental design. London: Chartered Institution of Building Services Engineers 2006.

(75) Oughton D, Hodkinson S. Faber \& Kell's Heating and Air-conditioning of Buildings. : Spon Press; 2008.

(76) Pitts A, bin Saleh J. Transition Spaces and Thermal Comfort-Opportunities for Optimising Energy Use.

(77) Kwong QJ, Adam NM. Perception of thermal comfort in the enclosed transitional space of tropical buildings. Indoor and Built Environment 2011;20(5):524-533. 